\title{
The incidence of alien species on the taxonomic, phylogenetic, and functional diversity of lentic and lotic communities dominated by Phragmites australis (Cav.) Steud
}

\author{
Maria Beatrice Castellani ${ }^{1, *}$ (1), Lorenzo Lastrucci ${ }^{2}$, Lorenzo Lazzaro $^{3}{ }^{(0)}$, Rossano Bolpagni ${ }^{4}(\mathbb{D}$, \\ Alice Dalla Vecchia ${ }^{4}(1)$ and Andrea Coppi ${ }^{1}(0)$ \\ ${ }^{1}$ Department of Biology, University of Florence, via Micheli 1, 50121 Florence, Italy \\ ${ }^{2}$ Natural History Museum, Botanical Collections, University of Florence, via G. La Pira 4, 50121 Firenze, Italy \\ ${ }^{3}$ Department of Biology, University of Florence, via G. La Pira 4, 50121 Florence, Italy \\ ${ }^{4}$ Department of Chemistry, Life Sciences and Environmental Sustainability, University of Parma, Parma, Italy
}

Received: 28 July 2021 / Accepted: 6 January 2022

\begin{abstract}
This study aims to investigate, for the first time, the multiple diversity harbored in plant communities dominated by $P$. australis, discriminating between lentic and lotic habitats. We focused on the incidence of alien species on taxonomical, phylogenetic and functional diversity. Although it was hypothesized that ecological differences between habitats (lentic vs. lotic) could lead to plant adaptive tradeoffs, results showed that the $P$. australis dominance affected overall plant diversity in the same way in both target habitats. Similarly, the two compared habitats hosted a similar alien species richness and relative abundance. Different results were observed based on whether the alien species richness or their relative abundance were considered regarding the incidence of alien species. Increasing alien species richness in lentic habitats resulted in increased taxonomic, phylogenetic and functional diversity. Instead, in lotic habitats, it promoted a decrease in taxonomic and functional diversity. In contrast, the increase in the relative abundance of alien species resulted in increased taxonomic, phylogenetic and functional diversity in both habitats. Choosing relative abundance vs richness of aliens in lotic stands can have a different impact in evaluating the effect of aliens on various components of diversity.
\end{abstract}

Keywords: Invasive plants / diversity indices / macrophyte / common reed beds / wetlands / Italy

\section{Introduction}

Alien plant invasion is one of the most important drivers of biodiversity loss and ecosystem degradation worldwide (Seebens et al., 2017; Bolpagni, 2021). Among the several deleterious impacts on native communities, invasive plants may produce dramatic changes in structure and function of invaded ecosystem (Blackburn et al., 2014; Lazzaro et al., 2020a). Among others, two main hypotheses attempt to predict the incidence of invasion based on the ecological differences between alien and native species within communities (Enders et al., 2020). Firstly, environmental filtering (Kembel and Hubbell, 2006) would ensure that alien species, with similar ecological optimum to native species, might have a greater possibility of establishing and spreading. This would mean that a part of the functional and phylogenetic space, originally

\footnotetext{
${ }^{*}$ Corresponding author: mariabeatrice.castellani@unifi.it
}

occupied by native species in communities, being filled by the alien ones (Delle Fratte et al., 2019). Secondly, the "Darwin's naturalization hypothesis" (Rejmánek, 1996) claims that invasion would increase functional and phylogenetic diversity, when compared to non-invaded communities (Funk et al., 2008). In fact, alien species might exploit unfilled ecological niches if they are functionally and/or phylogenetically different from the native ones (Thuiller et al., 2010).

Wetlands seem to be especially vulnerable to invasions: while they cover only a small portion of the earth's land mass, $24 \%$ of the world's most invasive plants are wetland species (Bolpagni, 2021). Several disturbances, such as creating canopy gaps, hydroperiod alteration and propagule dispersal routes, facilitates wetland invasion (Galatowitsch et al., 1999; Rejmánek, 2000; Miller and Zedler, 2003). Lentic and lotic habitats represent stand-alone systems, with its own physical and chemical characteristics, differing in local environmental conditions (e.g., habitat geometry, presence or absence of flow, time of water residence) as well as hydrological connectivity 
(Hutchinson, 1975; Wetzel, 2001). On the one hand, lentic habitats are closed depositional environments, often showing standing and shallow water, generally interconnected to the main canals of the drainage basin thanks to small water bodies, which in turn, limits the water level oscillations and influx-outflux of matter and organisms (Cristofoletti, 1981). Conversely, lotic habitats are open systems where the continuous water flow carries sediments and nutrients derived from underlying catchments (Cristofoletti, 1981) and serves as a vector of propagules dispersion. In this case, flowing water tends to be a limiting and controlling factor, stronger than in lentic environments. These different geomorphological and hydric conditions heavily affect the community structure (France and Duffy, 2006; Starzomski and Srivastava, 2007), the dispersion of aquatic taxa, and their coexistence in multiple sites (Bilton et al., 2001; Bolpagni and Dalla Vecchia, 2021).

Phragmites australis-dominated stands are the predominant component of submerged and emergent shores of lakes, swamps, pools, ponds, riverbanks and hydrological networks (Landucci et al., 2013), most often with water level ranging from slightly below the soil surface to one meter above ground level (Brix, 1988; Ostendorp, 1993; Ailstock and Cente 2000). Indeed, reed beds play a key structural and functional role in freshwater ecosystems. They offer a suitable environment for the protection of land-water transition ecosystems and their components (Orsomando and Catorci, 1991). In addition, these areas provide multiple services for humans such as flood control and improving water quality (Carpenter and Lodge, 1986; Engelhardt and Ritchie, 2011; Smith et al., 2009). For these reasons, plant communities dominated by $P$. australis are fundamental for the biodiversity conservation, in particular, in the Mediterranean areas where the anthropic activities, such as water drainage, changes in land use, pollution and soil erosion upstream, lead to lower values of functional diversity, favoring the invasion of alien species (Gigante et al., 2011).

Several studies described reed-dominated communities from floristic and phytosociological point of view or showed the effects of multiple factors, biotic and abiotic, on the integrity of these sensitive communities (i.e., Coppi et al., 2018; Lastrucci et al., 2016; Angelini et al., 2012; Gigante et al., 2011). On the other hand, to the best of our knowledge, no comparative analyses have been carried out in terms of plant diversity between reeds of lentic and lotic habitats and, as far as we know, studies integrating taxonomical, functional, and phylogenetic information are totally absent. As well, it lacks specific literature on the role of alien species on the structure and functions of reed-dominated communities. To date, studies only investigated the effect of $P$. australis as an alien species (i.e., Ailstock et al., 2001; Uddin and Robinson, 2017b). Recently, the increased availability of phylogenetic data, coupled with the huge development of informatics tools, has promoted the rapid expansion of studies on community ecology (Cadotte et al., 2010; Mouquet et al., 2012). The main idea behind this approach is to interpret taxa phylogenetic positions as result of evolutionary processes, such as extinction (Purvis et al., 2000), speciation (Winter et al., 2009) and biological invasion (Srivastava et al., 2012). It has already become widely accepted that merging the phylogenetic and functional information allows to better quantify the impact of disturbances and to understand the processes contributing on plant community dynamics (Flynn et al., 2011; Perronne et al., 2014; Dehling et al., 2014; Hao et al., 2018; Chun and Lee, 2019; Lazzaro et al., 2020b).

In both lentic and lotic environments, $P$. australis dominated communities host a variable number of subordinate or alien species, whose presence can vary differently among sites. In this contest, we can hypothesize that the community assembly rules operate under a series of filters showing spatially nested effects (de Bello et al., 2013), which determine (i) stochastically and time-depending, the pool of colonizing species' of a location; (ii) which species should be selected locally through abiotic filters (i.e., water flooding or canopy gaps); (iii) the set of coexisting species modulated by the positive and negative interactions between organisms (biotic filters) within communities.

This study aims to investigate, for the first time, (i) the taxonomical, functional, and evolutive diversity harbored in communities dominated by $P$. australis discriminating between lentic and lotic habitats; (ii) the contribution of alien species on lentic and lotic wetland vegetations dominated by $P$. australis, and (iii) their incidence on taxonomical, phylogenetic and functional diversity of these environments. The main hypothesis of this work was that lentic habitats would have a more incidence of competitive exclusion instead of lotic environments that, in turn, potentially showed a higher incidence of abiotic filters. This differentiated behavior may regulate the establishment and affirmation of alien species, with a higher expected number of alien taxa in lotic sites due to their greater vulnerability to physical and chemical disturbance (Rosset et al., 2017).

\section{Materials and methods}

\subsection{Dataset}

We assembled a dataset (Supplementary Material, Tab. S1) based on published studies of wetland plant communities from both central and northern Italy (Tab. S2), representative of the main lentic and lotic environments in the study area $(\mathrm{S} 3 \mathrm{a}, \mathrm{b})$. In the present work, the "lentic sites" include the environments not subject to direct influence of current action, such as lakes, ponds, or pools. Whereas all sites influenced by recurring flooding events have been included in the "lotic" systems. As to consider only reed-dominated communities, only the relevés with $P$. australis cover $\geq 50 \%$ or with BraunBlanquet values of 4 and 5 were extracted from the selected literature. In addition, new floristic and vegetational data from four localities (Lake Idro, Oglio riverscape, Busatello swamp, and the Reggio Emilia lowland) were collected to expand the geographical representativeness of our dataset. To maximize the comparability between studies and plots, both the size (from 2 to $100 \mathrm{~m}^{2}$ ) and the sampling date (from 1989 to 2020) of all relevés were considered in the analysis. In addition, to further ensure comparability among data in terms of ecological and climatic conditions, an altitudinal threshold was fixed (500 $\mathrm{m}$ a.s.1.), excluding all the relevés recorded above this limit. 


\subsection{Quantifying biodiversity}

The species abundance matrix (Tab. S1) was used to quantify three components of biodiversity: taxonomic, phylogenetic and functional diversity. For each component we calculated one metric based on species presence and one diversity metric weighted on species abundance.

Taxonomic diversity (TD) was estimated by two traditional metrics: species richness (SR), as the number of species in each plot, and Shannon's index $(\mathrm{H})$, which accounts for species richness and their relative abundance (Lamb et al., 2009). All analyses were performed in R 3.0 software using the "vegan" package vers. 2.5-7 (Oksanen et al., 2020).

Phylogenetic diversity (PD) was quantified using the Faith's phylogenetic diversity $\left(\mathrm{PD}_{\mathrm{F}}\right)$ metric (Faith, 1992), a measure of the cumulative evolutionary age used in conservation research (Forest et al., 2007, Morlon et al., 2011, Rodrigues and Gaston, 2002), and the Mean Pairwise Distance (phy.MPD) metric, the average evolutionary distance between all pairwise species in a plot (Webb, 2000). In contrast to $\mathrm{PD}_{\mathrm{F}}$, this metric does not compare values to a null model and it does not consider the number of taxa. $\mathrm{PD}_{\mathrm{F}}$ and phy.MPD calculations were performed with R software (R Core Team, 2017), using the "picante" package vers. 1.8.2 (Kembel et al., 2010) and the "PhyloMeasures" package vers. 2.1 (Tsirogiannis and Sandel, 2016) respectively. To compute these metrics, a phylogenetic tree was reconstructed using the online bioinformatics tool Phylomatic (Webb and Donoghue, 2005), matching the list of all our family/genus/ species according to APG III (Angiosperm Phylogeny Group, 2009). and the tip labels of phylogenetic megatree from Zanne et al. (2014).

To compute functional diversity metrics, we selected four traits related to the ecosystem function of interest, i.e., leaf economic spectrum and morphology traits: Leaf mass (LM), Leaf Area (LA), Specific Leaf Area (SLA) and Leaf Dry Matter Content (LDMC) (see Perez-Harguindeguy et al., 2016). Functional traits for each species were obtained from international trait databases, LEDA (Kleyer et al., 2008) and TRY (Kattge et al., 2020). In case multiple values were available for a single species, the average value of the trait was used. In addition, traits values of eight species (Cirsium creticum, Cyperus strigosus, Eclipta prostrata, Euphorbia palustris, Hibiscus moscheutos, Oenanthe silaifolia, Symphyotrichum squamatum and Typha minima), which were missing in the databases, were measured in this study (Tab. S4). Functional diversity (FD) of each plot was estimated using two multi-trait metrics: the functional richness (FRic), given by the volume occupied by the community in the multidimensional space (Villéger et al., 2008), and the Rao's quadratic entropy (RaoQ), which reflects the abundance of each species, as well as the pairwise functional difference between species. Both these metrics were chosen for their adequate power to detect assembly rules (Mouchet et al., 2010) and were performed with R software using the package "FD" vers. 1.0-12 (Laliberté et al., 2014).

\subsection{Data analysis}

The differences in taxonomic, evolutive, and functional diversity harbored in both lentic and lotic habitats dominated by $P$. australis were investigated by means of linear mixed models (LMMs). The models included a random structure with two random effect factors, one accounting for the different source of the data, and one accounting for the relevés surface. In LMMs, response variables were transformed adopting the one-parameter Box-Cox transformation (Box and Cox, 1964) to achieve normality of residuals. The LMMs were carried out in R software using "ImerTest" package version 3.1-3.

We evaluated the differences in alien species richness (A.SR) and in their relative abundance (A.RelAb) among the two types of habitat. Considering the high number of zeros (i.e., relevés not including alien species) we fitted two separated zero-inflated mixed models (ZIMMs), accounting for a double component in the models: a binary response in a logistic regression (i.e., the zero inflated model) and a non-zero response regression (i.e., the conditional model). The non-zero response regression was described by a Poisson family in case of A.SR, while a Gamma family has been adopted in case of A.RelAb. Indeed, A.SR was defined as the number of alien species in each plot (count data), while A.RelAb was calculated as relative cover of alien species at each plot (continuous percentage data). The models included a random structure with two random effect factors, one accounting for the different source of the data, and one accounting for the relevés surface. The ZIMMs were carried out in R software, using the package "glmmTMB" vers. 1.0.2.1 (Magnusson et al., 2017).

To evaluate the effect of habitat, and respectively of A.SR or A.RelAb, on all three components of biodiversity (TD, PD and FD) we fitted two series of LMMs, with a Gaussian distribution, in a full factorial ANOVA design (thus including the interaction terms). In this case all the indices were calculated excluding the alien species from the community matrix. As above the models included a random structure with two random effect factors, one accounting for the different source of the data, and one accounting for the relevés surface. The LMMs were carried out in R software using "ImerTest" package version 3.1-3. All plots were drawn using "effect" package version 4.2-0 (Fox, 1987).

\section{Results}

\subsection{Dataset}

The final dataset included 231 vegetational plots, of which 176 representative of lentic habitats and 55 of lotic habitats. A total of 208 vascular macrophyte species was recorded, 104 in lentic and 34 in lotic habitats. Among the 208 macrophytes, 25 were identified as alien species, of which nine were exclusive for lentic habitats and eight for the lotic ones (Tab. 1). The range of A.SR was from 0 to 3 in the lentic stands and from 0 to 7 in the lotic ones. Regarding the A.RelAb, it varied from 0 to 15.5 in the lentic stands and from 0 to 37.5 in the lotic ones (Tab. S5).

\subsection{Quantifying biodiversity}

Lentic and lotic habitats did not show significant differences in the diversity metrics (Tab. S6) The mean values of each diversity metric for both habitats are shown in Table 2. 
M.B. Castellani et al.: Knowl. Manag. Aquat. Ecosyst. 2022, 423, 5

Table 1. List of alien species exclusive for each habitat and shared among habitats. For each species, frequency (F) and relative abundance (A.RelAb) were also shown.

\begin{tabular}{|c|c|c|c|c|}
\hline \multirow[t]{2}{*}{ Species } & \multicolumn{2}{|c|}{ Lentic habitat } & \multicolumn{2}{|c|}{ Lotic habitat } \\
\hline & $\mathrm{F}$ & RelAb & $\mathrm{F}$ & RelAb \\
\hline Acorus calamus & 3 & 0.5 & & \\
\hline Bidens connata & 1 & 0.83 & & \\
\hline Eclipta prostrata & 2 & 1.17 & & \\
\hline Hibiscus palustris & 8 & 3.83 & & \\
\hline Humulus scandens & 12 & 19.53 & & \\
\hline Lemna minuta & 10 & 8.55 & & \\
\hline Parthenocissus quinquefolia & 3 & 2.17 & & \\
\hline Periploca graeca & 1 & 0.17 & & \\
\hline Sorghum halepense & 5 & 2.37 & & \\
\hline Amaranthus tuberculatus & & & 2 & 1.17 \\
\hline Cyperus glomeratus & & & 2 & 0.33 \\
\hline Eragrostis pectinacea & & & 1 & 0.17 \\
\hline Helianthus tuberosus & & & 1 & 0.17 \\
\hline Lonicera japonica & & & 1 & 5 \\
\hline Panicum dichotomiflorum & & & 2 & 0.33 \\
\hline Populus xcanadensis & & & 1 & 0.17 \\
\hline Sicyos angulatus & & & 2 & 2 \\
\hline Amorpha fruticosa & 17 & 3.29 & 1 & 3 \\
\hline Bidens frondosa & 29 & 1.13 & 5 & 3.9 \\
\hline Galega officinalis & 5 & 3.42 & 1 & 0.5 \\
\hline Paspalum distichum & 7 & 4 & 2 & 0.5 \\
\hline Solidago gigantea & 3 & 2.17 & 1 & 0.5 \\
\hline Symphyotrichum lanceolatum & 1 & 0.05 & 2 & 18.78 \\
\hline Symphyotrichum squamatum & 1 & 0.5 & 1 & 0.5 \\
\hline Xanthium italicum & 4 & 0.39 & 7 & 1.21 \\
\hline
\end{tabular}

Table 2. Mean value of each diversity metric in lentic and lotic habitats. Species Richness (SR), Shannon's diversity index (H), Mean Pairwise Distance (phy.MPD), Faith's phylogenetic diversity (PD), functional richness (FRic), functional Rao's quadratic entropy (RaoQ).

\begin{tabular}{lllllll}
\hline Habitat & $\mathrm{SR}$ & $\mathrm{H}$ & $\mathrm{PD}_{\mathrm{F}}$ & phy.MPD & FRic & RaoQ \\
\hline Lentic & 7.16 & 0.57 & 1282.19 & 276.97 & 2.39 & 0.85 \\
Lotic & 6.65 & 0.66 & 1245.94 & 298.70 & 2.35 & 1.07 \\
\hline
\end{tabular}

The SR metric varied from 1 to 21 (BU22) and from 1 to 14 (PANT11) species per plot, in lentic and lotic habitats, respectively. Moreover, lentic communities showed a higher number of monospecific stands (ms) than the lotic ones (21 and one respectively). Regarding $\mathrm{H}$ index, values ranged from 0 (ms) to 1.82 (BU64) in lentic communities, and from $0(\mathrm{~ms})$ to 1.98 (PANT6) in lotic ones (Tab. S5).

The evolutive reconstruction of lentic and lotic macrophytes' communities was shown in supplementary materials (newick tree $\mathrm{S} 7$ ). Regarding $\mathrm{PD}_{\mathrm{F}}$ metric, values of lentic comminuities ranged from 640.15 (14EVi05) to 2776.68 (BU06), while values of lotic ones ranged from 640.15 (ARNO15) to 2007.38 (PANT11). Looking at the phyMPD metric, values ranged from 0 $(\mathrm{ms})$ to 515.43 (SERR3) in lentic communities, and from $0(\mathrm{~ms})$ to 417.09 (ARNO11) in lotic ones (Tab. S5).

The FRic metric ranged from 0 (ms) to 20.30 (MASSAC14) in lentic communities, and from 0 (ms) to 8.21 (PANT 5) in lotic ones. Looking at the RaoQ metric, values of lentic communities ranged from $0(\mathrm{~ms})$ to 11.52 (PORTA01), while values of lotic ones ranged from 0 (ms) to 3.44 (ARNO1) (Tab. S5).

\subsection{Differences in A.SR and in A.RelAb as a function of habitat type}

No significant effect of the habitat type was found as to both the alien species richness (A.SR) and the relative abundance of alien species (A.RelAb) (Tab. S8).

\subsection{Effect of habitat, alien species and their interaction on TD, PD and FD}

A.SR: Model results showed that only in lentic habitats, the taxonomic, phylogenetic and functional diversity increased at 
A

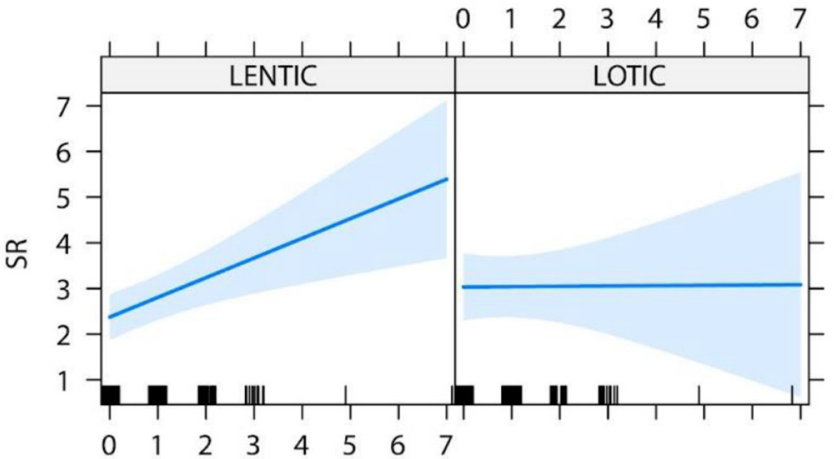

C

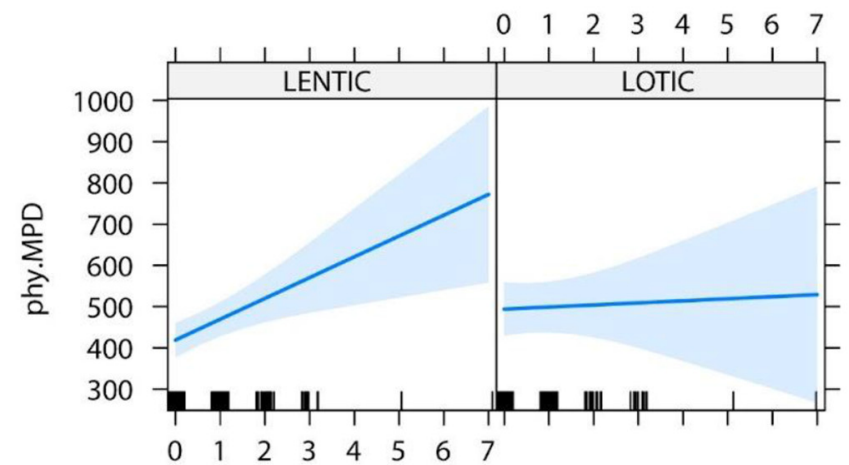

E

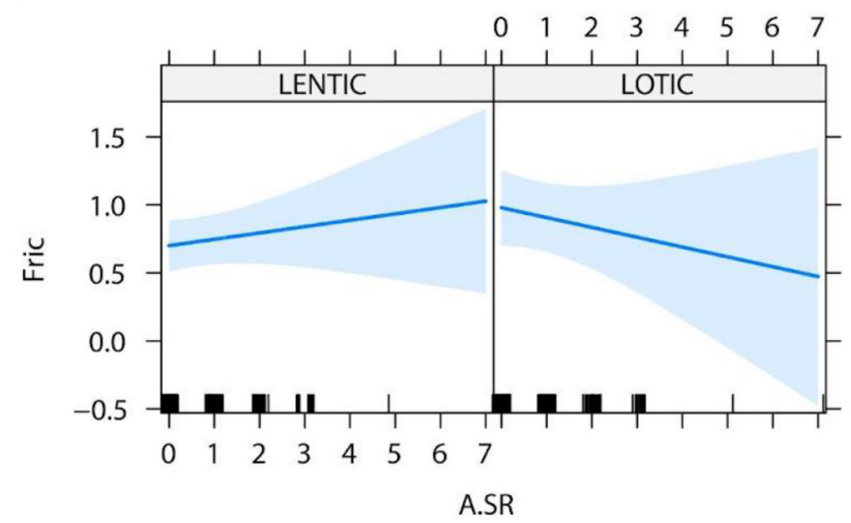

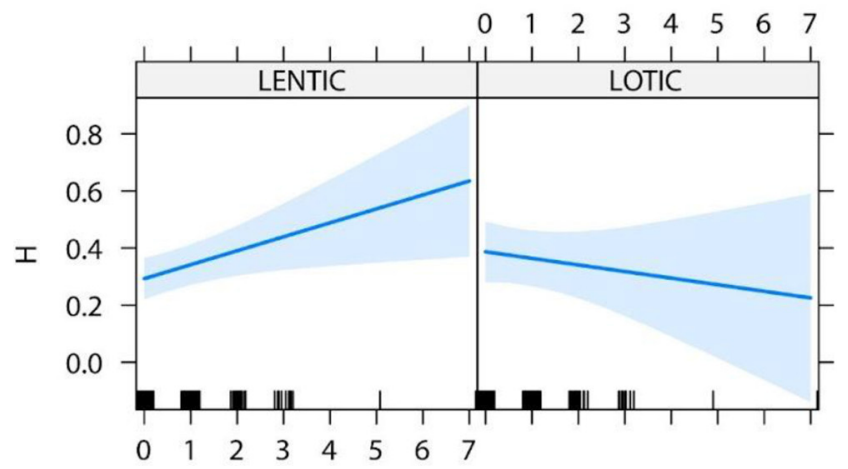

D

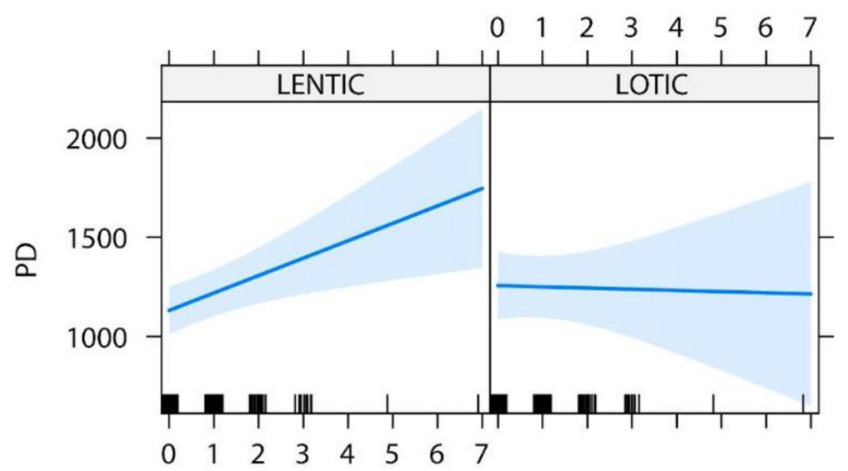

$\mathrm{F}$

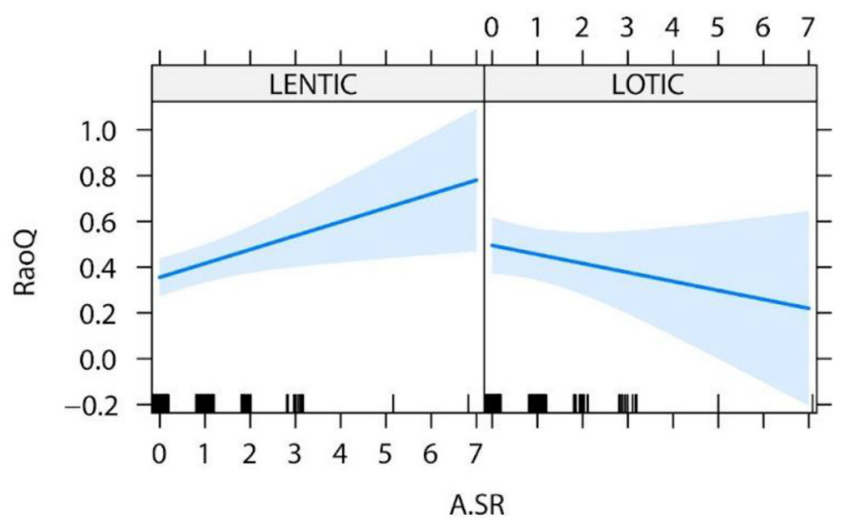

Fig. 1. Interaction plot from the linear mixed models showing the effect of the alien species richness (A.SR) on the different diversity metrics in both habitats. Species Richness (SR), Shannon's diversity index (H), Mean Pairwise Distance (phy.MPD), Faith's phylogenetic diversity (PD), functional richness (FRic), functional Rao's quadratic entropy (RaoQ).

increasing species richness. Regarding lotic habitats, taxonomic and functional diversity metrics decreased at increasing species richness, while phylogenetic diversity remained almost unchanged (slightly higher). Specifically, the $\mathrm{H}$ and RaoQ metrics were influenced by the Habitat:A.SR interaction $(P=0.044$, Fig. 1B; $P=0.017$, Fig. 1F; Tab. S9), while the phyMPD metric was influenced by A.SR $(P=0.039$, Fig. $1 \mathrm{D}$; Tab. S9). In addition, despite having similar trends compared to the other biodiversity components, the $\mathrm{SR}, \mathrm{PD}_{\mathrm{F}}$ and FRic metrics were only marginally influenced by A.SR + Habitat:
A.SR, Habitat:A.SR and Habitat, respectively $(P<0.1$; Fig. 1A, C, E; Tab. S9).

A.RelAb: The effect of the A.RelAb on the three components of biodiversity (TD, PD and FD) was not statistically different between both habitats (Tab. S10). However, there was a positive correlation between the A. RelAb and three metrics: H, phy.MPD and RaoQ $(P=0.014$, Fig. 2B; $P=0.032$, Fig. 2D; $P=0.016$, Fig. 2F; Tab. S10). Even in this case, the SR metric was only marginally influenced by A.RelAb $(P<0.1$, Fig. 2A; Tab. S10). 


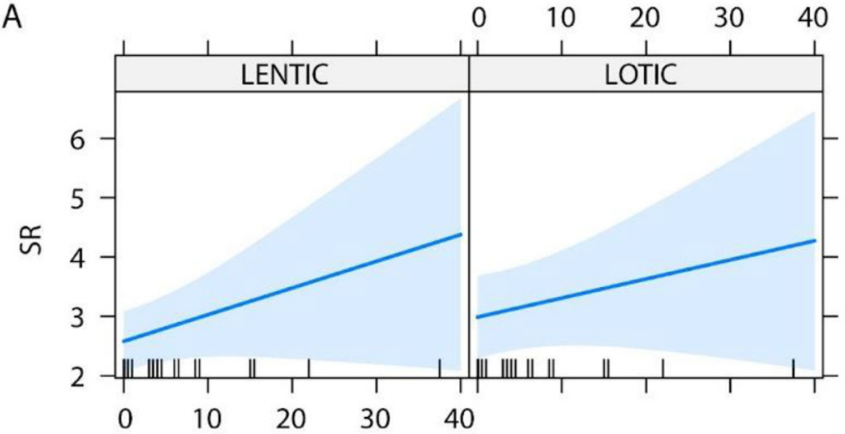

C

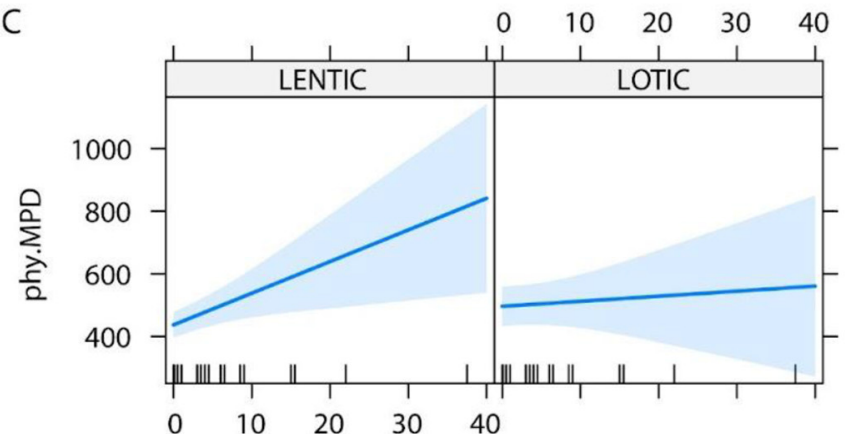

$\mathrm{E}$

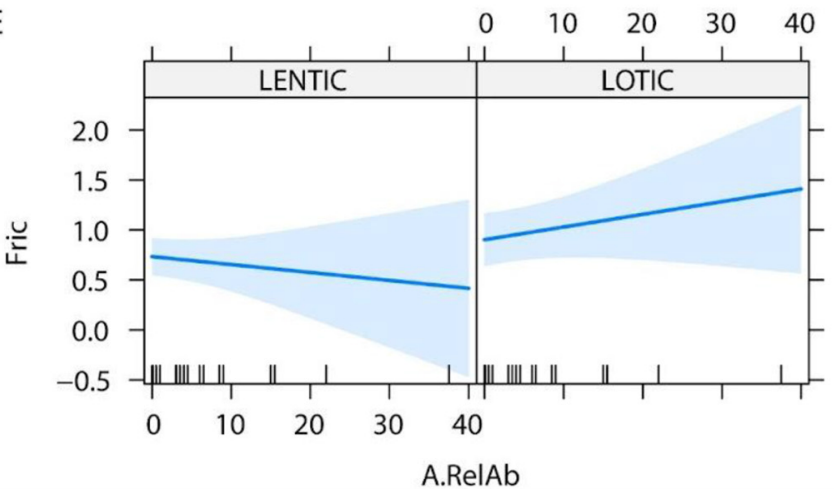

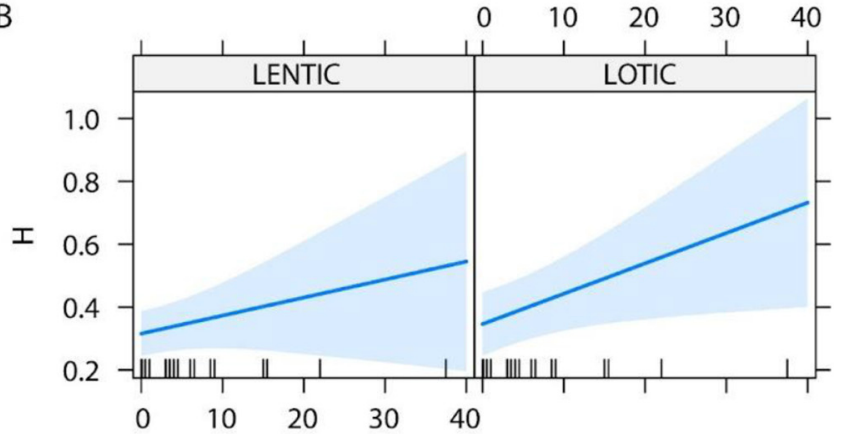

D
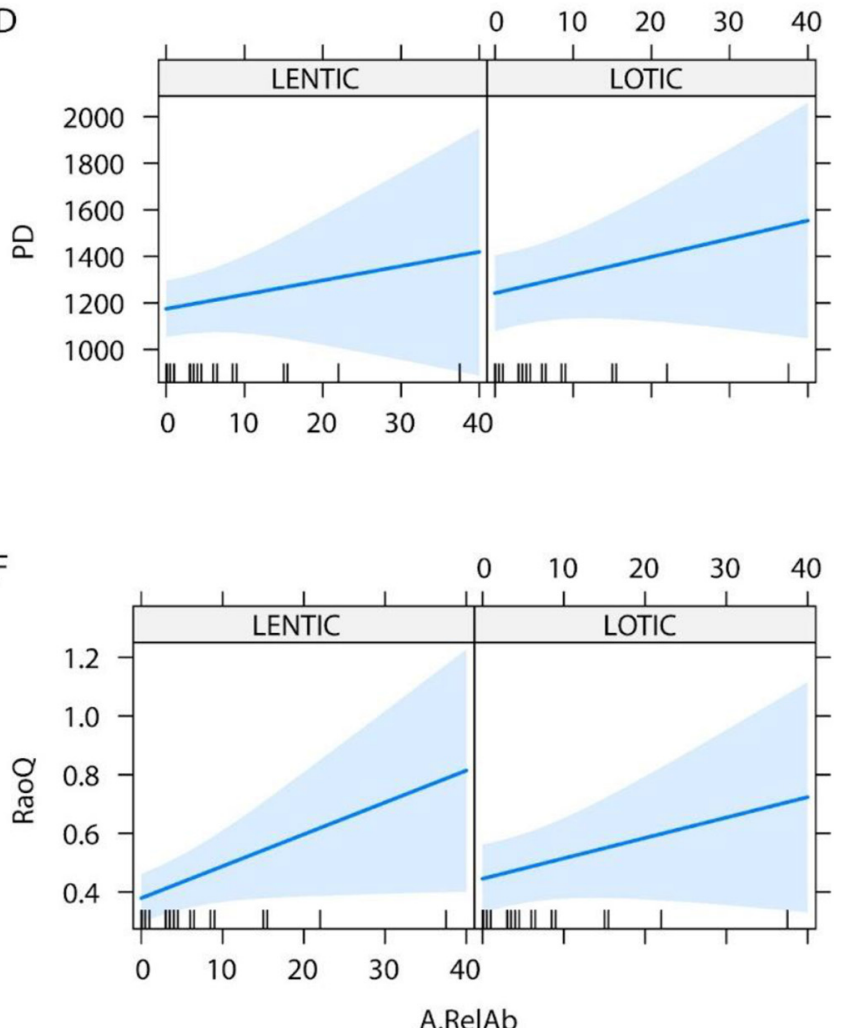

Fig. 2. Interaction plot from the linear mixed models showing the significant effect of the relative abundance of alien species (A.RelAb) on the different diversity metrics in both habitats. Species Richness (SR), Shannon's diversity index (H), Mean Pairwise Distance (phy.MPD), Faith's phylogenetic diversity (PD), functional richness (FRic), functional Rao's quadratic entropy (RaoQ).

\section{Discussion}

In this study, we applied a multidimensional approach including taxonomic, functional and phylogenetic data to enhance our basic understanding of plant diversity between $P$. australis dominated communities. To the best of our knowledge, the outcome of this study carried out for the first time a comparison of the above-mentioned diversity facets of habitats dominated by $P$. australis across lentic and lotic conditions. Moreover, we analysed, for the first time, the incidence of alien species on the "multiple diversity" of reeddominated plant communities for lentic and lotic habitats.
Although it was hypothesised that the ecological differences between lentic or lotic habitats can lead to plant adaptive trade-offs (Cristofoletti, 1981; Wetzel, 2001; Starzomski and Srivastava, 2007), thus shaping the assembly rules of plant communities, the outcomes of our work showed a substantial lack of differences in taxonomic, functional and phylogenetic diversity between lentic and lotic communities. Therefore, it is conceivable that the $P$. australis dominance affected the overall plant diversity in the same way in both target habitats. Uddin and Robinson (2017a) noted that the taxonomic diversity of reed-dominated plant communities differed significantly according to the density of $P$. australis. 
Since we considered a reduced range of coverage rates (the highest Braun-Blanquet values possible, notably 4 and 5), this may explain why no differences were observed in the taxonomic indices calculated. Miler et al. (2014) analysed the biochemical and morphological differences between river and lake macrophytes. They showed that the observed differences could be explained by wind disturbance in lentic sites and by the water regime disturbance in lotic habitats. However, $P$. australis is an "ecosystem engineer species" par excellence, and its dense stands play an essential role as a wind and wave breaker (Takeda and Kurihara 1988; Vymazal 2011; Karstens et al., 2016). Therefore, the same high level of reeds coverage may have buffered different abiotic factors and led to similar levels of functional diversity across habitats. Moreover, the dominance of $P$. australis in dense stands may have promoted biotic interactions such as competitive exclusion, promoting random phylogenetic assemblage of communities in both habitats, and no phylogenetic differences across lentic and lotic stands. Similar outcomes were shown by Veldkornet et al. (2019) for riparian plant communities of streams and estuaries dominated by common reed. Most of the stands in estuaries showed no phylogenetic structure suggesting the coexistence of plant species structured mainly by biotic interactions (Veldkornet et al., 2019, and references therein: Mayfield and Levine, 2010; Barber et al., 2017). However, beyond the direct effects of $P$. australis, riparian macrophytes show a wide ecological adaptability, being able to establish and develop both in lotic and lentic ecosystems (such as $P$. australis itself). In the present study, we focused on lowland areas (below $500 \mathrm{~m}$ a.s.1.) where rivers tend to acquire physical features very similar to those of lentic habitats (e.g., due to slowed flows or damming), which could justify the compositional convergence between sites in terms of "companion species" of $P$. australis. Furthermore, the global alteration of inland waters, both in terms of water quantity and quality, has huge effects on aquatic species that are among the most threatened biodiversity facets (Dudgeon, 2019; van Rees et al., 2021). In heavily exploited landscapes, this translates into wet hyper-simplified plant communities characterized by an everincreasing structural similarity (Bolpagni and Piotti, 2016; Bolpagni et al., 2016).

Similarly, we found that the lentic and lotic habitats host a comparable alien species richness and relative abundance. This is in line with the findings by Boggero et al. (2014) which did not notice differences between lentic and lotic habitats comparing different invaded biological communities. It should further be noted here that in our case indeed the definition of lotic ecosystems did include very different river ecosystems from each other, with a high variability of water regimes. Actually, the intensity of water flow is known as a pivotal factor that drives alien cover and richness in river ecosystems (see also below) (Heidbüchel and Hussner, 2020; Bolpagni, 2021), and it is conceivable that including it in our analysis could have led to different results. However, as previously discussed, we investigated a wide set of sites subjected to a huge range of human impacts that can completely change the hydrological functioning of aquatic ecosystems, greatly reducing our ability to assess their local effects. Further efforts will be needed in this direction to improve our understanding of human-mediated effects to $P$. australis-communities invasibility.

\subsection{Incidence of alien plant species}

Regarding the incidence of alien species on the different components of biodiversity, different results were observed based on whether the alien species richness or their relative abundance were considered. Already Brummer et al. (2016), in similar environments (i.e., gravel floodplain ecosystems), recognized that alien cover and richness were shaped differently by different variables (such as water flow, substrate texture). This supports the idea that alien richness and relative abundance may also relate to different impacts on the colonized communities (Montanari et al., 2020; Bolpagni and Dalla Vecchia, 2021). As to the role of the relative abundance it should be noted that while it is generally agreed that there is a strong positive relationship among alien species abundance and subsequent impacts, it has been shown that even at low abundance, alien plants may impact native plant richness at both local and landscape scales (Bernard-Verdier and Hulme, 2019).

The impact of alien species richness (A.SR) was different between lentic and lotic habitats, increasing A.SR in lentic habitats resulted in increased taxonomic, phylogenetic and functional diversity. Supporting the "Darwin's naturalization hypothesis" (DNH) (Rejmánek, 1996), alien species exploit unfilled ecological niches (Thuiller et al., 2010) and make the phylogenetic and functional space more saturated, providing a new subset of traits and evolutionary origins in invaded communities (Funk et al., 2008). On the other hand, the higher richness of alien species in lotic habitats promoted a decrease in taxonomic and functional diversity. Based on these observations, alien species established in lotic stands occupy a portion of the functional space within the native communities' range, thus leading to an increased similarity between species in invaded communities. In addition, the phy. MPD metric showed that the communities most invaded had similar or slightly higher phylogenetic distance than non-invaded ones, suggesting close phylogenetic relatedness of invaders to native species (Lososová et al., 2015). These results are consistent with the hydrologic disturbance to which lotic habitats are subjected. This abiotic factor must then be considered as the main driver in filtering alien species with ecological requirements and advantageous traits similar to those of native species (Campos, 2010). According to the hypothesis of environmental filtering (Kembel and Hubbell, 2006), alien species with high similarity to resident species tend to have similar ecological adaptations as native species and have a better chance to establish and spread. In contrast, the increase in phylogenetic diversity in lentic habitat is consistent with less intense hydrological disturbance and greater habitat stability than lotic ones. In these environments, the closed depositional conditions may promote coexistence of species from distant lineages via niche differences (Kitagawa et al., 2015; Lososová et al., 2015).

In contrast to patterns of A.SR, the impact of relative abundance of alien species (A.RelAb) was not different between lentic and lotic habitats. The increase in A.RelAb resulted in increased taxonomic, phylogenetic and functional diversity in both habitats. On the one hand, results suggest that DNH is confirmed for lentic communities where the more abundant alien plant species entering the communities promote the taxonomic, functional and phylogenetic dispersion. On the other hand, choosing relative abundance vs richness of 
aliens in lotic stands can have a different impact in evaluating the effect of aliens on the different components of diversity. Previous studies supported that the influences of invasive alien species on plant taxonomic diversity may vary with degree of invasion (Dong et al., 2015). Two studies, based only on one alien species, showed that a low degree (less than $50 \%$ ) of relative abundance of the alien species was associated with a significant increase in the taxonomic diversity of plant communities (Wang et al., 2018, 2021). As taxonomic diversity, also functional diversity may vary with degree of invasion. McGrannachan and McGeoch (2019), examining the effect of multispecies' invasion to the community level, showed that functional diversity of the understorey community increased until the relative abundance of alien species remained low $(\sim 20 \%)$. Within our framework, P. australis was the most abundant species (above $64.5 \%$ of mean coverage), and none of the alien species had a relative abundance greater than $35 \%$. As in forest ecosystems, the low degree of relative abundance of alien species may not have negatively affected the diversity metrics, confirming the importance of this aspect in evaluating the diversity of reed communities.

\section{Conclusions}

Based on a large dataset (231 plots), referred to a key conservation area for wetland plant diversity at the global scale (Northern and Central Italy; Bolpagni et al., 2018), the present paper offered new insights on different levels of diversity (taxonomic, functional, and evolutionary) in communities dominated by $P$. australis.

Main outcomes revealed a substantial comparability between lentic and lotic P. australis communities in terms of diversity facets. The dominance of common reed affected the diversity of plant communities of both target habitats more than the absolute presence of alien species. Further investigations are still required to widen the dataset to rebalance the number of relevés concerning the two macro-typologies of this study (lotic vs lentic), which are here strongly biased towards lentic habitats, and to include other geographical areas. This will allow to fully clarify the shaping role of $P$. australis on wetland plant diversity, offering essential information to design affective ecological recovery plans, as well as guaranteeing adequate levels of protection to one of the biodiversity components (i.e., the freshwater one) at greatest risk of global extinction.

\section{Supplementary Material}

Table S1. Dataset based on published and new vegetational relevés of reed-dominated plant communities.

Table S2. The list of published vegetational relevés of reeddominated plant communities.

Table S3.a: List, abbreviation names, and coordinates of the macro-localities investigated. S3.b: Map of of the macrolocalities investigated.

Table S4. Traits values of species which were missing in the databases.

Table S5. The taxonomic, phylogenetic and functional diversity values of each plot.
Table S6. Analysis of variance table for the differencies in taxonomic, phylogenetic and functional diversity indexes among lentic and lotic habitats.

Table S7. Evolutive reconstruction of lentic and lotic macrophytes' communities.

Table S8. Summary table for zero-inflated mixed models evaluating the differences in alien species richness and in their relative abundance among the two types of habitat.

Table S9. Analysis of variance table for the effect of habitat and alien species richness on taxonomic, phylogenetic and functional diversity indexes.

Table S10. Analysis of variance table for the effect of habitat and alien relative abundance on taxonomic, phylogenetic and functional diversity indexes.

The Supplementary Material is available at https://www.kmae. org $/ 10.1051 / \mathrm{kmae} / 2022001 / \mathrm{olm}$.

Acknowledgments. This work has been supported by the project "macroDIVERSITY", funded by the Ministry of Education, University and Research, PRIN 2017 [grant 2017CTH94H]. A special thanks to Dr. Carla Lambertini (University of Bologna).

\section{References}

Ailstock MS, Cente E. 2000. Adaptive strategies of common reed Phragmites australis. The Role of Phragmites in the Mid-Atlantic Region. April, 17: 1-7.

Ailstock MS, Norman CM, Bushmann PJ. 2001. Common reed Phragmites australis: control and effects upon biodiversity in freshwater nontidal wetlands. Restor Ecol 9: 49-59.

Angelini P, Rubini A, Gigante D, Reale L, Pagiotti R, Venanzoni R., 2012. The endophytic fungal communities associated with the leaves and roots of the common reed (Phragmites australis) in Lake Trasimeno (Perugia Italy) in declining and healthy stands. Fungal Ecol 5: 683-693.

Angiosperm Phylogeny Group. 2009. An update of the Angiosperm Phylogeny Group classification for the orders and families of flowering plants: APG III. Bot J Linn Soc 161: 105-121.

Barber NA, Jones HP, Duvall MR, Wysocki WP, Hansen MJ, Gibson DJ. 2017. Phylogenetic diversity is maintained despite richness losses over time in restored tallgrass prairie plant communities. $J$ Appl Ecol 54: 137-144.

Bernard-Verdier M, Hulme PE. 2019. Alien plants can be associated with a decrease in local and regional native richness even when at low abundance. $J$ Ecol 107: 1343-1354.

Bilton DT, Foggo A, Rundle SD. 2001. Size permanence and the proportion of predators in ponds. Archiv für Hydrobiologie 451-458.

Blackburn TM, Essl F, Evans T, et al. 2014. A unified classification of alien species based on the magnitude of their environmental impacts. PLoS Biol 12: e1001850.

Boggero A, Basset A, Austoni M, et al.2014. Weak effects of habitat type on susceptibility to invasive freshwater species: an Italian case study. Aquat Conserv 24: 841-852.

Bolpagni R. 2021. Towards global dominance of invasive alien plants in freshwater ecosystems: the dawn of the Exocene? Hydrobiologia 848: 2259-2279.

Bolpagni R, Dalla Vecchia A. 2021. Pioneer annual vegetation of gravel-bed rivers: First insights on environmental drivers from three Apennine streams. J Limnol 80: 2052. 
Bolpagni R, Laini A, Stanzani C, Chiarucci A. 2018. Aquatic Plant Diversity in Italy: Distribution, Drivers and Strategic Conservation Actions. Front Plant Sci 9: 116.

Bolpagni R, Piotti A. 2016. The importance of being natural in a human-altered riverscape: role of wetland type in supporting habitat heterogeneity and the functional diversity of vegetation. Aquat Conserv 26: 1168-1183.

Bolpagni R, Racchetti E, Laini A. 2016. Fragmentation and groundwater supply as major drivers of algal and plant diversity and relative cover dynamics along a highly modified lowland river. Sci Total Environ 568: 875-884.

Box GEP, Cox DR. 1964. An analysis of transformations (with discussion). J R Stat Soc Series B 26: 211-252.

Brix H. 1988. Light-dependent variations in the composition of the internal atmosphere of Phragmites australis (Cav.) Trin. ex Steudel. Aquat Bot 30: 319-329.

Brummer TJ, Byrom AE, Sullivan JJ, Hulme PE. 2016. Alien and native plant richness and abundance respond to different environmental drivers across multiple gravel floodplain ecosystems. Divers Distrib 22: 823-835.

Cadotte MW, Jonathan Davies T, Regetz J, Kembel SW, Cleland E, Oakley TH. 2010. Phylogenetic diversity metrics for ecological communities: integrating species richness abundance and evolutionary history. Ecol lett 13: 96-105.

Campos JA. 2010. Flora alóctona del Pars Vasco y su influencia en la vegetación. Mem. Doc. (inéd.). Univ. País Vasco (UPV/EHU), Leioa.

Carpenter SR, Lodge DM. 1986. Effects of submersed macrophytes on ecosystem processes. Aquat Bot 26: 341-370.

Chun JH, Lee CB. 2019. Temporal changes in species phylogenetic and functional diversity of temperate tree communities: Insights from assembly patterns. Front Plant Sci 10: 294.

Coppi A, Lastrucci L, Cappelletti D, et al 2018. AFLP approach reveals variability in Phragmites australis: implications for its dieback and evidence for genotoxic effects. Front Plant Sci 9: 386.

Cristofoletti A. 1981. Geomorfologia Fluvial Canal Fluvial. Voll Edgard Blucher Ltda São Paulo SP 313p.

Dalle Fratte M, Bolpagni R, Brusa G, et al 2019. Alien plant species invade by occupying similar functional spaces to native species. Flora 257: 151419.

de Bello F, Vandewalle M, Reitalu T, et al 2013. Evidence for scaleand disturbance-dependent trait assembly patterns in dry seminatural grasslands. $J$ Ecol 101: 1237-1244.

Dehling DM, Fritz SA, Töpfer T, et al 2014. Functional and phylogenetic diversity and assemblage structure of frugivorous birds along an elevational gradient in the tropical Andes. Ecography 37: 1047-1055.

Dong LJ, Yu HW, He WM. 2015. What determines positive neutral and negative impacts of Solidago canadensis invasion on native plant species richness?. Sci Rep 5: 1-9.

Dudgeon D. 2019. Multiple threats imperil freshwater biodiversity in the Anthropocene. Current Biology 29: R960-R967.

Enders M, Havemann F, Ruland F, et al 2020. A conceptual map of invasion biology: Integrating hypotheses into a consensus network. Glob Ecol Biogeogr 29: 978-991.

Engelhardt KA, Ritchie ME. 2001. Effects of macrophyte species richness on wetland ecosystem functioning and services. Nature 411(6838): 687-689.

Faith DP. 1992. Conservation evaluation and phylogenetic diversity. Biol Conserv 61: 1-10.

Flynn DF, Mirotchnick N, Jain M, Palmer MI, Naeem S. 2011. Functional and phylogenetic diversity as predictors of biodiversityecosystem-function relationships. Ecology 92: 1573-1581.
Forest F, Grenyer R, Rouget M, et al 2007. Preserving the evolutionary potential of floras in biodiversity hotspots. Nature 445: 757-760.

Fox J. 1987. Effect displays for generalized linear models. Sociol Methodol 347-361.

France KE, Duffy JE. 2006. Diversity and dispersal interactively affect predictability of ecosystem function. Nature 441: 11391143.

Funk JL, Cleland EE, Suding KN, Zavaleta ES. 2008. Restoration through reassembly: plant traits and invasion resistance. Trends Ecol Evol 23: 695-703.

Galatowitsch SM, Anderson NO, Ascher PD. 1999. Invasiveness in wetland plants in temperate North America. Wetlands 19: 733-755.

Gigante D, Venanzoni R, Zuccarello V. 2011. Reed die-back in southern Europe? A case study from Central Italy. Comptes rendus biologies 334: 327-336.

Hao M, Zhang C, Zhao X, Von Gadow K. 2018. Functional and phylogenetic diversity determine woody productivity in a temperate forest. Ecol Evol 8: 2395-2406.

Heidbüchel P, Hussner A. 2020. Falling into pieces: In situ fragmentation rates of submerged aquatic plants and the influence of discharge in lowland streams. Aquat Bot 160: 103164.

Hutchinson GE. 1975. A Treatise on Limnology. Vol 3 Limnological Botany, John Wiley \& Sons, New York.

Karstens S, Jurasinski G, Glatzel S, Buczko U. 2016. Dynamics of surface elevation and microtopography in different zones of a coastal Phragmites wetland. Ecol Eng 94: 152-63.

Kattge J, Boenisch G, Diaz S, et al. 2020. TRY plant trait database enhanced coverage and open access. Glob Change Biol. 26: 119188.

Kembel SW, Hubbell SP. 2006. The phylogenetic structure of a Neotropical forest tree community. Ecology 87: 86-99.

Kembel SW, Cowan PD, Helmus MR, et al 2010. Picante: R tools for integrating phylogenies and ecology. Bioinformatics 26: $1463-1464$.

Kitagawa R, Mimura M, Mori AS, Sakai A. 2015. Topographic patterns in the phylogenetic structure of temperate forests on steep mountainous terrain. Aob Plants 7: plv134.

Kleyer M, Bekker RM, Knevel IC, et al 2008. The LEDA Traitbase: a database of life-history traits of the Northwest European flora. $J$ Ecol 96: 1266-1274.

Laliberté E, Legendre P, Shipley B, Laliberté ME. 2014. Package 'FD' Measuring functional diversity from multiple traits and other tools for functional ecology. $R$ package version 10-12.

Lamb EG, Bayne E, Holloway G, et al. 2009. Indices for monitoring biodiversity change: Are some more effective than others?. Ecol Indic 9: 432-444.

Landucci F, Gigante D, Venanzoni R, Chytrý M. 2013. Wetland vegetation of the class Phragmito-Magno-Caricetea in central Italy. Phytocoenologia 43: 67-100.

Lastrucci L, Gigante D, Vaselli O, et al 2016. Sediment chemistry and flooding exposure: a fatal cocktail for Phragmites australis in the Mediterranean basin?. Ann Limnol-Int J Lim 52: 365-377 EDP Sciences.

Lazzaro L, Bolpagni R, Buffa G, et al. 2020a. Impact of invasive alien plants on native plant communities and Natura 2000 habitats: State of the art gap analysis and perspectives in Italy. $J$ Environ Manage 274: 111-140.

Lazzaro L, Lastrucci L, Viciani D, Benesperi R, Gonnelli V, Coppi A. 2020b. Patterns of change in $\alpha$ and $\beta$ taxonomic and phylogenetic diversity in the secondary succession of semi-natural grasslands in the Northern Apennines. PeerJ 8: e8683. 
Lososová Z, de Bello F, Chytrý M, et al 2015. Alien plants invade more phylogenetically clustered community types and cause even stronger clustering. Glob Ecol Biogeogr 24: 786-794.

Magnusson A, Skaug H, Nielsen A, et al 2017. Package 'glmmTMB'. R Package Version 02.0.

Mayfield MM, Levine JM. 2010. Opposing effects of competitive exclusion on the phylogenetic structure of communities. Ecol. Lett. 13:1085-1093.

McGrannachan CM, McGeoch MA. 2019. Multispecies plant invasion increases function but reduces variability across an understorey metacommunity. Biol Invasions 21: 1115-1129.

Miler O, Albayrak I, Nikora V, O'Hare M. 2014. Biomechanical properties and morphological characteristics of lake and river plants: implications for adaptations to flow conditions. Aquat $\mathrm{Sci}$ 76: 465-481.

Miller RC, Zedler JB. 2003. Responses of native and invasive wetland plants to hydroperiod and water depth. Plant Ecol 167: 57-69.

Montanari I, Buldrini F, Bolpagni R, et al 2020. Role of irrigation canal morphology in driving riparian flora in over-exploited catchments. Comm Ecol 21: 121-132.

Morlon H, Schwilk DW, Bryant JA, et al 2011. Spatial patterns of phylogenetic diversity. Ecol. Lett. 14: 141-149.

Mouchet MA, Villéger S, Mason NW, Mouillot D. 2010. Functional diversity measures: an overview of their redundancy and their ability to discriminate community assembly rules. Funct Ecol 24: 867-876.

Mouquet N, Devictor V, Meynard CN, et al. 2012. Ecophylogenetics: advances and perspectives. Biol Rev 87: 769-785.

Oksanen J, Blanchet FG, Friendly M, Kindt R, Legendre P, McGlinn D. 2020. vegan: community ecology package. R package version 2.5-7.

Orsomando E, Catorci A. 1991. Carta della vegetazione del comprensorio Trasimeno. Editrice Grafica l'Etruria Cortona.

Ostendorp W. 1993. Reed bed characteristics and significance of reeds in landscape ecology.

Perez-Harguindeguy N, Diaz S, Garnier E, et al. 2016. Corrigendum to: new handbook for standardised measurement of plant functional traits worldwide. Aust $J$ Bot 64: 715-716.

Perronne R, Mauchamp L, Mouly A, Gillet F. 2014. Contrasted taxonomic phylogenetic and functional diversity patterns in seminatural permanent grasslands along an altitudinal gradient. Plant Ecol Evol 147: 165-175.

Purvis A, Agapow PM, Gittleman JL, Mace GM. 2000. Nonrandom extinction and the loss of evolutionary history. Science 288: 328-330.

Rejmánek M. 1996. A theory of seed plant invasiveness: the first sketch. Biol Conserv 78: 171-181.

Rejmánek M. 2000. Invasive plants: approaches and predictions. Austral Ecol 25: 497-506.

Rodrigues AS, Gaston KJ. 2002. Maximising phylogenetic diversity in the selection of networks of conservation areas. Biological Conservation 105: 103-111.

Rosset V, Ruhi A, Bogan MT, Datry T. 2017. Do lentic and lotic communities respond similarly to drying? Ecosphere 87: e01809.

Seebens H, Blackburn TM, Dyer EE, et al. 2017. No saturation in the accumulation of alien species worldwide. Nat Commun 8: 1-9.

Smith SM, Roman CT, James-Pirri MJ, Chapman K, Portnoy J, Gwilliam E. 2009. Responses of plant communities to incremental hydrologic restoration of a tide-restricted salt marsh in southern New England (Massachusetts USA). Restor Ecol 17: 606-618.

Srivastava DS, Cadotte MW, MacDonald AAM, Marushia RG, Mirotchnick N. 2012. Phylogenetic diversity and the functioning of ecosystems. Ecol Lett 15: 637-648.

Starzomski BM, Srivastava DS. 2007. Landscape geometry determines community response to disturbance. Oikos 116: 690-699.

Takeda S, Kurihara Y. 1988. The effects of the reed Phragmites australis (Trin.) on substratum grain-size distribution in a salt marsh. J Oceanogr Soc Japan 44: 103-112.

Thuiller W, Gallien L, Boulangeat I, et al. 2010. Resolving Darwin's naturalization conundrum: a quest for evidence. Divers Distrib 16: 461-475.

Tsirogiannis C, Sandel B. 2016. PhyloMeasures: a package for computing phylogenetic biodiversity measures and their statistical moments. Ecography 39: 709-714.

Uddin MN, Robinson RW. 2017a. Responses of plant species diversity and soil physical-chemical-microbial properties to Phragmites australis invasion along a density gradient. Sci Rep 7: 1-13.

Uddin MN, Robinson RW. 2017b. Allelopathy and resource competition: the effects of Phragmites australis invasion in plant communities. Bot Stud 58: 1-12.

van Rees CB, Waylen KA, Schmidt-Kloiber A, et al. 2021. Safeguarding freshwater life beyond 2020: Recommendations for the new global biodiversity framework from the European experience. Conserv Lett 14: e12771.

Veldkornet DA, Adams JB, Boatwright JS, Rajkaran A. 2019. Barcoding of estuarine macrophytes and phylogenetic diversity of estuaries along the South African coastline. Genome 62: 585-595.

Villéger S, Mason NW, Mouillot D. 2008. New multidimensional functional diversity indices for a multifaceted framework in functional ecology. Ecology 89: 2290-2301.

Vymazal J. 2011. Plants used in constructed wetlands with horizontal subsurface flow: a review. Hydrobiologia 674: 133-156.

Wang C, Jiang K, Liu J, Zhou J, Wu B. 2018. Moderate and heavy Solidago canadensis $L$. invasion are associated with decreased taxonomic diversity but increased functional diversity of plant communities in East China. Ecol Eng 112: 55-64.

Wang C, Cheng H, Wu B, et al. 2021. The functional diversity of native ecosystems increases during the major invasion by the invasive alien species Conyza canadensis. Ecol Eng 159: 106093.

Webb CO. 2000. Exploring the phylogenetic structure of ecological communities: an example for rain forest trees. Am Natur 156: $145-155$.

Webb CO, Donoghue MJ. 2005. Phylomatic: tree assembly for applied phylogenetics. Mol Ecol Notes 5: 181-183.

Wetzel RG. 2001. Limnology: Lakes and River Ecosystems. 3rd edition. Academic press.

Winter M, Schweiger O, Klotz S, et al. 2009. Plant extinctions and introductions lead to phylogenetic and taxonomic homogenization of the European flora. PNAS 106: 21721-21725.

Zanne AE, Tank DC, Cornwell WK, et al. 2014. Three keys to the radiation of angiosperms into freezing environments. Nature 506: 89-92.

Cite this article as: Castellani MB, Lastrucci L, Lazzaro L, Bolpagni R, Dalla Vecchia A., Coppi A. 2022. The incidence of alien species on the taxonomic, phylogenetic, and functional diversity of lentic and lotic communities dominated by Phragmites australis (Cav.) Steud. Knowl. Manag. Aquat. Ecosyst., 423, 5. 